\title{
PROCESAMIENTO DE GUANACOS DURANTE EL ARCAICO TARDÍO DEL NORTE SEMIÁRIDO DE CHILE: UN ACERCAMIENTO ZOOARQUEOLÓGICO Y ESPACIAL INTRASITIO
}

\author{
GUANACO-PROCESSING DURING THE LATE ARCHAIC IN THE SEMI-ARID \\ NORTH OF CHILE: A ZOOARCHAEOLOGICAL AND SPATIAL INTRASITE \\ $A P P R O A C H$
}

\author{
Patricio López M.1,2, Isabel Cartajena F..$^{1,2}$, Boris Santander ${ }^{3,4}$, \\ Daniela Villalón ${ }^{5}$, Alina Sáez ${ }^{6}$ y Bárbara Rivera ${ }^{7}$
}

\begin{abstract}
Se presenta el análisis zooarqueológico de los restos de guanacos (Lama guanicoe) recuperados de la ocupación Arcaica Tardía del sitio MAU085, emplazado en el valle de Mauro, Norte Semiárido chileno. Este análisis tuvo por objetivo entender la organización espacial del sitio, el cual corresponde a un campamento de cazadores-recolectores orientado al procesamiento de animales, entre otras actividades. El conjunto de análisis realizados apunta a una ocupación no estival y reiterada del sitio desde el 3.200 hasta los 2.500 años a.p., con una organización espacial relacionada a actividades de procesamiento, descarte y transporte principalmente de guanacos, junto a la confección y preparación de artefactos líticos de apropiación.
\end{abstract}

Palabras claves: Arcaico Tardío, guanacos, Norte Semiárido, Chile.

Here we present the zooarchaeological analysis of guanaco (Lama guanicoe) remains recovered from the Late Archaic occupation in the MAU085 site, located in the Mauro Valley, in the semi-arid north of Chile. The aim of this study is to understand the spatial organization of this hunter-gatherer site mainly focused on animal processing activities. The results suggest a redundant seasonal (non estival) occupation of the site between 3,200 to 2,500 yr BP, showing a marked spatial organization related principally to guanaco processing, transport and disposal activities together with the elaboration and preparation of lithic appropriation artifacts. Key words: Late Archaic, guanacos, semi-arid north, Chile.

El conocimiento de las sociedades cazadorasrecolectoras que habitaron el Norte Semiárido de Chile durante el Arcaico Tardío proviene de trabajos que han enfatizado la construcción de secuencias cronológicas y culturales, relaciones estilísticas y artefactuales, patrones de asentamiento, junto a la funcionalidad de sitios a base de análisis de diversas evidencias arqueológicas (Ampuero y Rivera 1971; Cornejo y Jackson 2004; Méndez y Jackson 2004, 2008; Méndez et al. 2009). No obstante, en los últimos años se ha comenzado a explorar la dimensión espacial tanto a nivel intrasitio (Solar et al. 2010) como a una escala mayor, que apunta a comprender la movilidad entre sitios y espacios geográficos definidos (Méndez et al. 2009).

A pesar de los diversos esfuerzos, los antecedentes arqueológicos de las ocupaciones del Arcaico Tardío (ca. 4.000-2.000 años a.p.) al interior del Norte Semiárido siguen siendo escasos en comparación con los registros de la costa (Cornejo y Jackson 2004; Méndez y Jackson 2004). Mientras que en las ocupaciones costeras la economía estuvo orientada al consumo de una amplia gama de recursos de disponibilidad inmediata (Méndez y Jackson

1 Departamento de Antropología, Facultad de Ciencias Sociales, Universidad de Chile, Ignacio Carrera Pinto 1045, Ñuñoa, Santiago, Chile.patriciolopezmend@gmail.com; icartaje@uchile.cl

2 ARQMAR-Centro de Investigación en Arqueología Marítima del Pacífico Sur Oriental, Santiago, Chile.

3 Departamento de Antropología, Universidad Alberto Hurtado, Almirante Barroso 10, Santiago, Chile. bsantander@uahurtado.cl

4 Área de Prehistoria, Universitat Rovira i Virgili e IPHES, Institut Català de Paleoecologia Humana i Evolució Social, Tarragona, España.

5 Calle Del Pontífice 522, Maipú, Chile. danielavillalon27@gmail.com

$6 \quad$ Calle Argomedo 65 depto. 1211A, Santiago, Chile. alisaez@ug.uchile.cl

7 Vitacura 10171 depto. B36, Santiago, Chile. briveramaro@gmail.com 
2004), para las poblaciones interiores, la caza del guanaco fue la principal orientación económica. Hasta el presente, las evidencias provenientes de sitios excavados en el interior corresponden en su mayoría a campamentos a cielo abierto y abrigos rocosos con rastros de grupos de cazadores recolectores con una marcada movilidad residencial y con posibles traslados estacionales entre ambas vertientes de los Andes (Méndez y Jackson 2008; Méndez et al. 2009).

Recientes trabajos conducidos en la zona precordillerana del valle de Mauro permitieron registrar 107 sitios arqueológicos, donde llama la atención el bajo número de sitios arcaicos. Solo dos de ellos pudieron ser asignados al Arcaico Tardío: MAU033 (ca. 2.500 años a.p.) y MAU085 (ca. 3.200 a 2.500 años a.p.), correspondiendo el primero de ellos a un contexto funerario con escasas evidencias domésticas.

Contrariamente, el sitio MAU085 presenta una alta densidad y diversidad de evidencias artefactuales y ecofactuales durante casi 700 años de ocupación. Entre los vestigios recuperados cabe destacar el gran conjunto de restos óseos de guanacos (Lama guanicoe) registrados. La extensión del sitio, la excavación en áreas de grandes superficies, la delimitación de diversos sectores y la buena preservación del yacimiento, permiten no solo el estudio exhaustivo del conjunto arqueofaunístico, sino también el uso de otros indicadores contextuales y el análisis de la distribución espacial, comprender las actividades de procuramiento, transporte, procesamiento, preparación, consumo y descarte final. De esta forma, el cúmulo de datos obtenidos para el sitio MAU085 es clave para abordar y comprender por primera vez el aprovechamiento integral del guanaco en un contexto de cazadoresrecolectores del interior del Norte Semiárido durante el Arcaico Tardío.

\section{El Sitio MAU085: Evidencias Arqueológicas, Áreas de Actividad y Cronología}

El Norte Semiárido (NSA en adelante) es un área intermedia entre el Norte Árido y la Zona Central de Chile $\left(26^{\circ}-33^{\circ} \mathrm{S}\right)$. Como franja intermedia, presenta actualmente en su clima y vegetación rasgos transicionales entre el desierto del norte y los ambientes mediterráneos del sur (Veit 1993). Dentro de esta franja, el valle de Mauro ( $31^{\circ} 57^{\prime} \mathrm{S}-71^{\circ} 01^{\prime} \mathrm{O}, \sim 900 \mathrm{msm}$ ) fue un espacio profusamente transitado y ocupado tanto por sociedades cazadoras-recolectoras como por grupos con economías agropastoriles consolidadas (López et al. 2015). El emplazamiento de este valle en una cuenca preandina formativa del actual estero Pupío, favoreció el asentamiento humano desde los ca. 7.500 años a.p. hasta el presente.

El sitio MAU085 se emplaza sobre una loma de orientación aproximada $\mathrm{N}-\mathrm{S}$, al poniente del estero Mauro ( $31^{\circ} 58^{\prime} \mathrm{S}-71^{\circ} 01^{\prime} \mathrm{O}, \sim 878 \mathrm{msm}$ ) (Figura 1A). La localización de este yacimiento es privilegiada, puesto que domina ampliamente el valle por el este y la quebrada donde se emplaza el estero por el sur y el oeste. El sector presenta una pendiente suave y el asentamiento ocupa un área aproximada de $4.448 \mathrm{~m}^{2}$. La excavación cubrió una superficie de $224 \mathrm{~m}^{2}$ por medio de 56 unidades de $2 \mathrm{~m} \times 2 \mathrm{~m}^{1}$, privilegiando la excavación en áreas de vastos sectores (Figura 1B, C y D). En todo el sitio se identificaron tres unidades estratigráficas, la Capa $\mathrm{B}$, con un promedio de $30 \mathrm{~cm}$ de espesor, que concentra la ocupación asignada al Arcaico Tardío (AT en adelante), mientras que la capa superior, denominada Capa A, presenta una ocupación asignada al período Alfarero Temprano (PAT en adelante). Por último la Capa C corresponde a un depósito estéril con escasos restos arqueológicos que migraron desde la Capa B.

Mediante las excavaciones fue posible identificar cuatro áreas, segregadas espacial y cronológicamente: (1) Área Quincha, corresponde a un sector dominado por una concentración horizontal y semiovalada de quincha (arcilla cocida con fibras vegetales entremezcladas), asociada a escasos restos culturales y ecofactuales asignados al PAT (Figura 1B). (2) Área de Actividad, caracterizada por restos óseos (Lama guanicoe, microfauna y mesofauna) y artefactos líticos, desechos de talla y de retoque, entre otros (Figuras 1B y 1C). (3) Área de Contextos Funerarios AT, la que se emplaza en un sector más alejado y se caracteriza por la inhumación de tres individuos humanos datados para el Arcaico Tardío, cuyos contextos estaban asociados a pequeños fogones planos y en cubeta, sin ajuar u ofrendas. Por último, (4) Área de Contextos Funerarios PAT, localizada al Oeste del sitio con cuatro contextos funerarios con lactantes y perinatos asignados al Período Alfarero Temprano (Figuras 1B).

La secuencia cronológica de las ocupaciones arcaicas tardías va desde los $3.180 \pm 63$ cal. a.p. a $\operatorname{los} 1.965 \pm 32$ cal. a.p. Esta secuencia se estableció a 

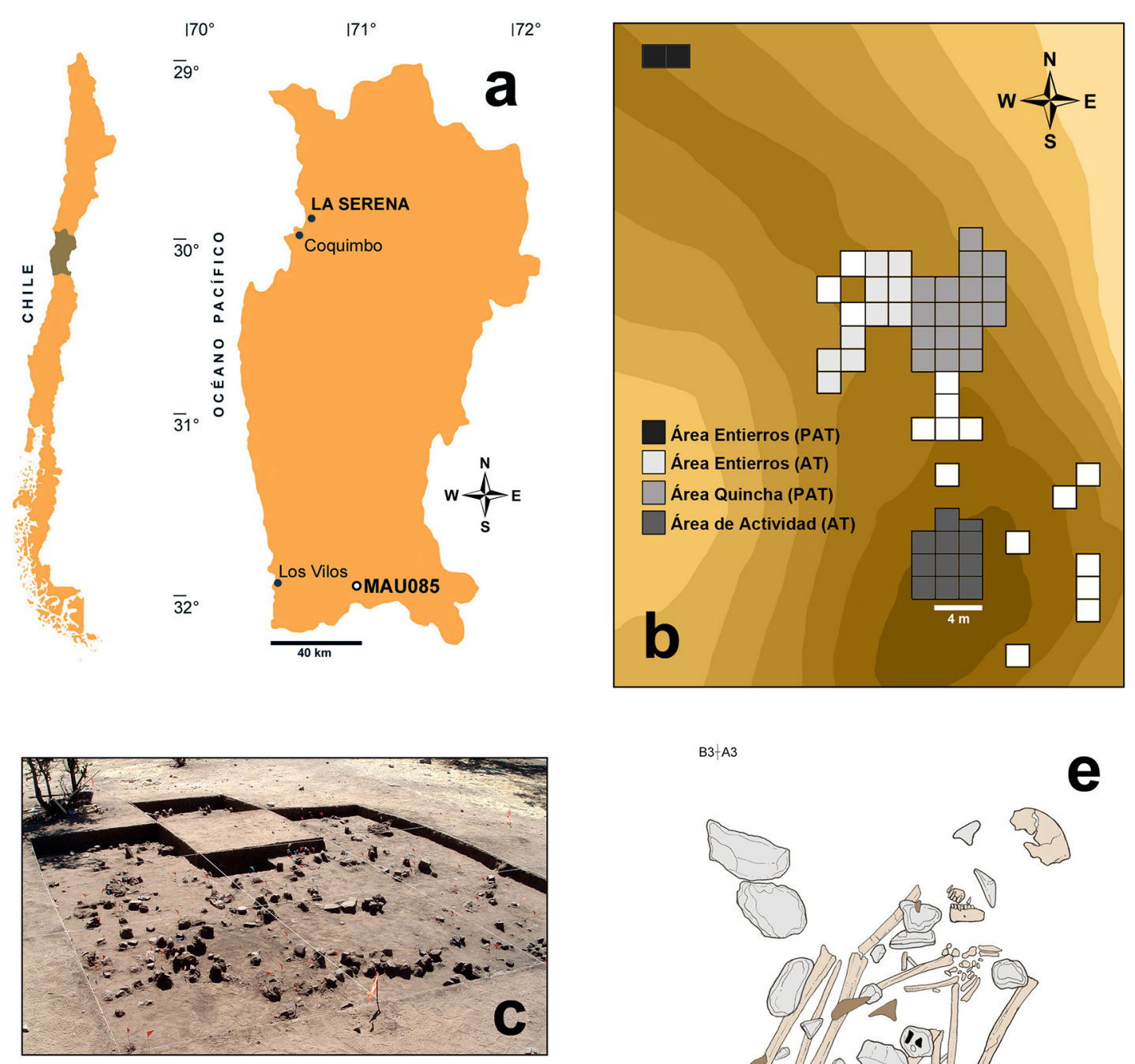

$\mathrm{B} 3+\mathrm{A} 3$
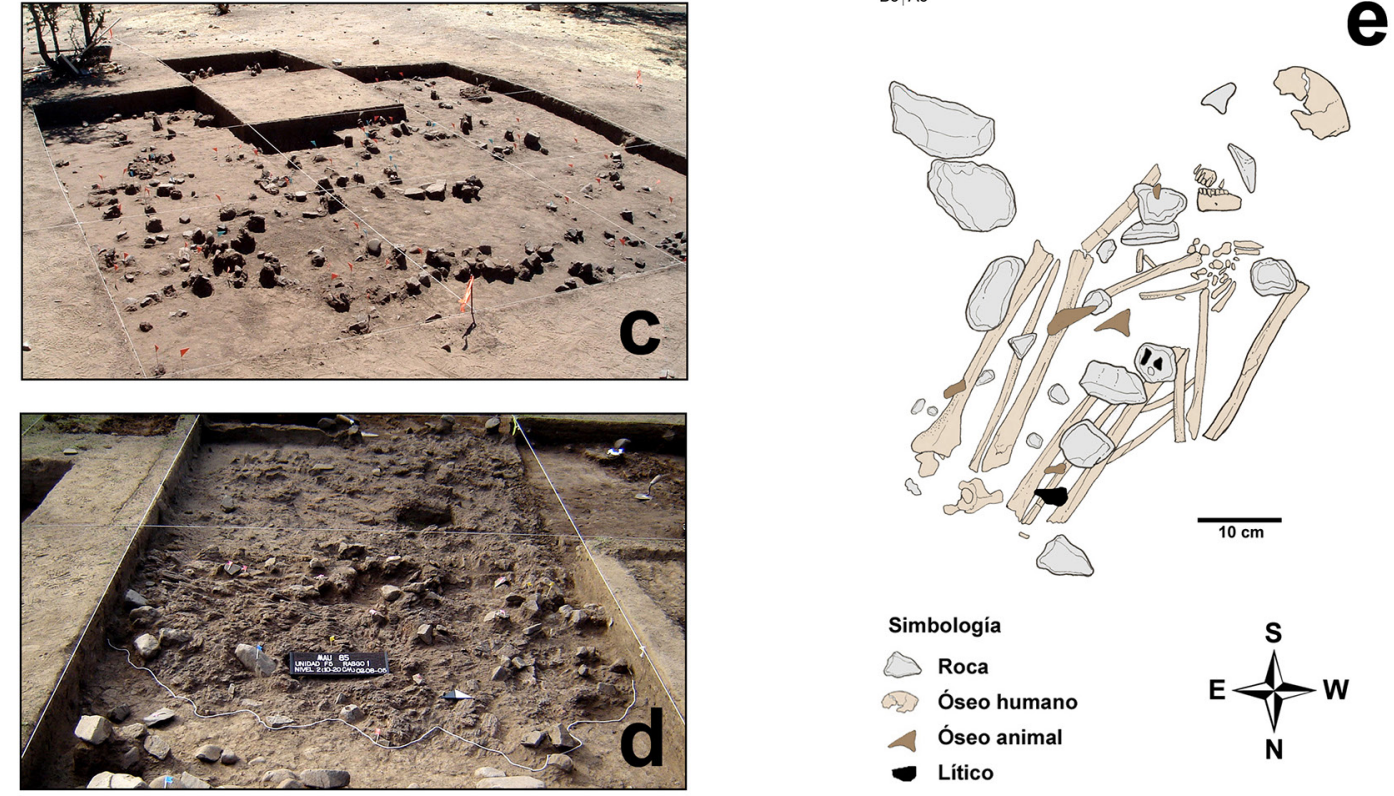

Figura 1. (A) Ubicación del sitio MAU085, (B) Áreas definidas en el sitio (C) Excavación del "Área de Actividad" datada para el AT; (D) "Área de Quincha" de afiliación PAT; (E) Detalle de uno de los contextos funerarios datados para el AT.

(A) Location of the MAU085 site, (B) defined areas in the site; $(C)$ excavation of the Late Archaic (AT) "Activity Area"; $(D)$ excavation of the Early Ceramic Period (PAT) "Quincha Area"; (E) Late Archaic (AT) funerary context detail.

partir de una batería de 21 fechados radiocarbónicos provenientes de restos de fauna, carbón y restos bioantropológicos (Pavlovic et al. 2011) (Tabla 1).
Se realizaron modelos de edad/profundidad con las diferentes evidencias datadas, utilizando OxCal, Built 8.2, que señalan al menos una pulsación de 
Tabla 1. Fechados radiocarbónicos (CAIS, University of Georgia) obtenidos del material arqueológico del sitio MAU085 (Pavlovic et al. 2011). Calibraciones realizadas en el marco del presente trabajo ${ }^{1}$.

Radiocarbon dates (CAIS, University of Georgia) of the MAU085 site (Pavlovic et al. 2011). Calibration of radiocarbon dates performed for this paper.

\begin{tabular}{lccccc}
\hline ID Laboratorio & Unidad/Rasgo & Prof. media (z) & Muestra & ${ }^{14}$ C años a.p. & $\begin{array}{c}14 \text { C años cal a.p. } \\
(\mathrm{m})\end{array}$ \\
\hline UGAMS 10911 & F16 & -45 & Lama guanicoe & $2.060 \pm 25$ & $1.965 \pm 32$ \\
UGAMS 10912 & L5 & -35 & Lama guanicoe & $2.470 \pm 25$ & $2.463 \pm 105$ \\
UGAMS 10913 & F16 & -35 & Lama guanicoe & $2.670 \pm 25$ & $2.754 \pm 23$ \\
UGAMS 10914 & F14 & -20 & Lama guanicoe & $2.710 \pm 25$ & $2.775 \pm 28$ \\
UGAMS 10915 & H17 & -5 & Lama guanicoe & $2.330 \pm 25$ & $2.323 \pm 53$ \\
UGAMS 10916 & E14 & -35 & Lama guanicoe & $2.430 \pm 25$ & $2.415 \pm 82$ \\
UGAMS 10917 & F16 & -55 & Lama guanicoe & $2.690 \pm 25$ & $2.764 \pm 25$ \\
UGAMS 10918 & F16 & -35 & Lama guanicoe & $2.540 \pm 25$ & $2.586 \pm 80$ \\
UGAMS 9926 & K8 & -25 & Carbón & $2.840 \pm 25$ & $2.899 \pm 45$ \\
UGAMS 9927 & G6 & -15 & Carbón & $2.670 \pm 25$ & $2.754 \pm 23$ \\
UGAMS 9928 & L4 & -35 & Carbón & $2.770 \pm 25$ & $2.819 \pm 35$ \\
UGAMS 9929 & G7 & - & Carbón & $2.830 \pm 25$ & $2.886 \pm 46$ \\
UGAMS 9930 & F15 & -45 & Carbón & $2.800 \pm 25$ & $2.847 \pm 44$ \\
UGAMS 9931 & C17/Fogón & -65 & Carbón & $2.910 \pm 25$ & $2.987 \pm 56$ \\
UGAMS 9932 & D17/Rasgo 1 & -45 & Carbón & $2.870 \pm 25$ & $2.929 \pm 48$ \\
UGAMS 9933 & C17-C18/Rasgo 2 & -90 & Carbón & $2.870 \pm 25$ & $2.929 \pm 48$ \\
UGAMS 9934 & A13 & -35 & Carbón & $2.890 \pm 25$ & $2.956 \pm 53$ \\
UGAMS 9935 & F5 & - & Carbón & $2.860 \pm 25$ & $2.918 \pm 45$ \\
UGAMS 9937 & F6/ SE & -35 & Carbón & $3.040 \pm 25$ & $3.180 \pm 63$ \\
UGAMS 11003 & A13 / Individuo 1 & -35 & Óseo humano & $2.450 \pm 30$ & $2.440 \pm 100$ \\
UGAMS 11004 & C17 / Individuo 3 & -85 & Óseo humano & $3.030 \pm 25$ & $3.164 \pm 61$ \\
\hline
\end{tabular}

1 Los fechados radiocarbónicos fueron nuevamente calibrados con el programa OxCal 4.2 (Build 83, Bronk Ramsey 2009), utilizando la curva de calibración ShCal 13 (Hogg et al. 2013), en este caso se utilizó la fecha que entrega la mediana. Además se realizaron modelos de edad/profundidad utilizando nuevamente OxCal (Bronk Ramsey 2008; Bronk Ramsey y Lee 2013) para graficar las diferencias de depositación de las muestras fechadas.

las ocupaciones concentradas en unos 740 años, entre el $3.180 \pm 63$ a.p. y el $2.440 \pm 100$ cal. a.p. (Figuras 2A y 2B). Dichos modelos son consistentes con la depositación del sitio, que presenta una mayor densidad de evidencias materiales durante el AT entre los 30 y $40 \mathrm{~cm}$ de profundidad. Los tres sectores antes mencionados estarían siendo utilizados de manera conjunta en esta pulsación de 740 años, en donde el Área de Actividad, es la que presenta mayor densidad y concentración de ocupaciones en el periodo AT. El Área Quincha, descrita como PAT, presenta una datación asignable al AT de mayor antigüedad que el resto del sitio, fecha obtenida a partir de restos de carbones que pudieron migrar desde el Área de Actividad, ya que no se registraron rastros arqueológicos del AT asociados a esta área. Lo anterior sugiere que MAU085 es un sitio principalmente Arcaico, cuyas evidencias cronológicas y arqueológicas respaldan una intensidad de reocupaciones a lo largo del período que es constante y que únicamente se detiene a partir de los $\sim 1.900$ años cal. a.p., momento en el cual existiría un cese en las ocupaciones de grupos cazadores-recolectores acerámicos hasta la aparición de evidencias alfareras 500 años más tarde ( 1.400 cal. a.p.).

El componente AT comprende restos líticos compuestos por abundante registro de desechos de talla bifacial, gran cantidad de puntas de proyectil, sobre todo apedunculadas, cuchillos bifaciales y unifaciales, raspadores, cepillos, raederas, tajadores y chopping tools (Jackson y Peralta 2011). Este conjunto lítico enfatiza un modo de vida sustentado en la caza, esperable para grupos arcaicos del Holoceno Tardío, y con morfologías artefactuales similares a grupos sincrónicos asentados en la costa meridional del NSA (Jackson y Peralta 2011). Un aspecto recurrente en el AT es el uso de pigmentos, que en el caso del sitio MAU085 es abundante, sobre todo el caso del ocre, rojo y hierro oligisto (Latorre 2012). 


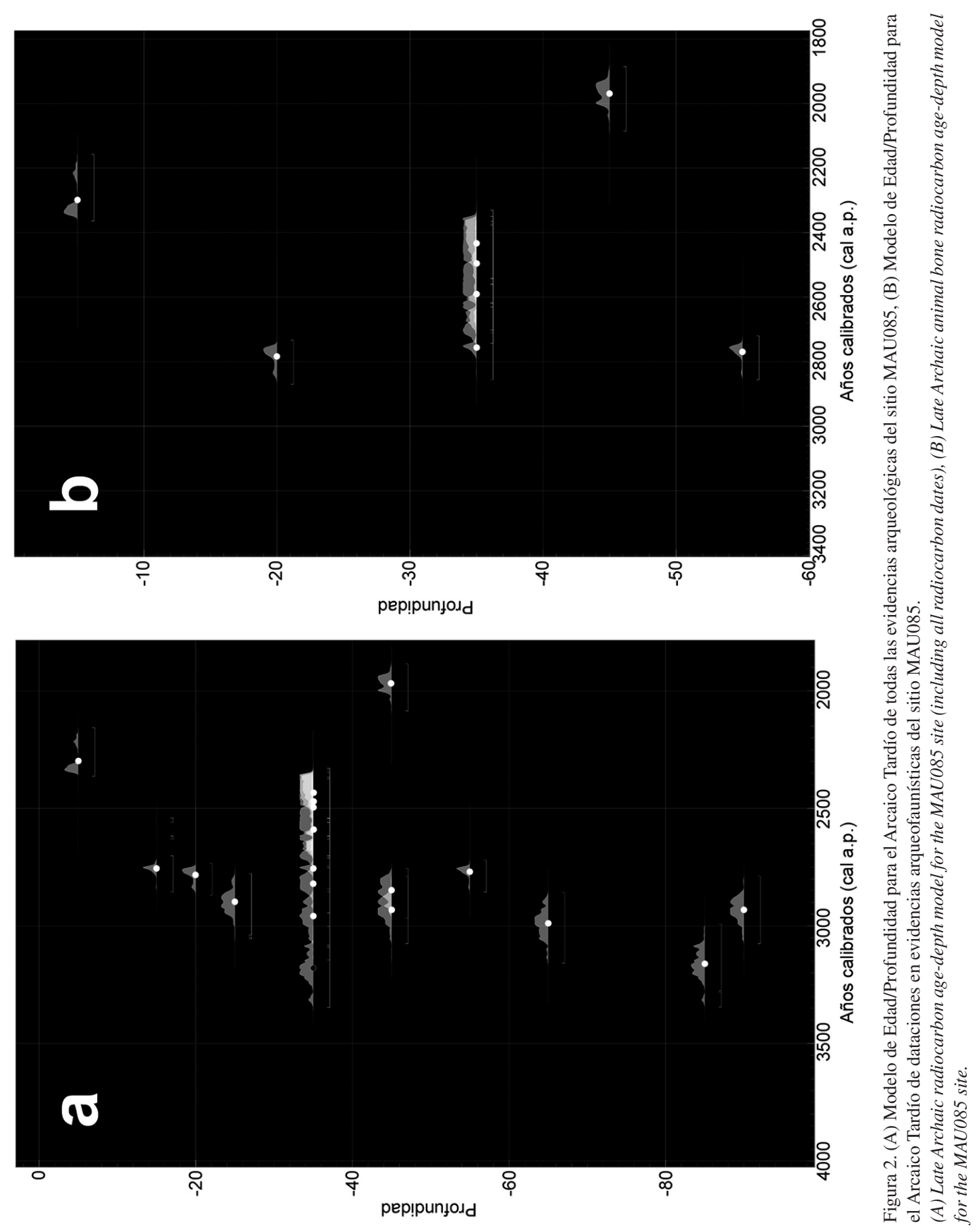


Por su parte, las evidencias carpológicas del sitio son escasas y corresponden a Amaranthus sp. (amaranto), Anacardiaceae (Familia del litre y molle entre otras especies), Echinopsis sp. (quisco), Copiapoa sp. (cactus), Chenopodium sp., Fabaceae (leguminosas), Galium sp. (relbún), Muehlenbeckia hastulata (quilo) y Poaceae (gramíneas). Dentro de un fogón datado para la ocupación AT se registró Chenopodium quinoa (quinua), lo que indica algún grado de horticultura o bien intercambio con grupos con manejo y control de esta especie (Belmar y Quiroz 2011).

\section{Muestra Zooarqueológica y Metodología Utilizada}

Se analizaron 218.426 especímenes osteofaunísticos. Sin embargo, para efectos de este trabajo se consideraron exclusivamente los restos provenientes de la Capa B -que representa a la ocupación AT-con 160.270 especímenes óseos. Para el análisis y siguiendo la metodología utilizada en trabajos anteriores (López et al. 2015), se consideraron diversas medidas de cuantificación (NISP, MNE, MAU y \%MAU), con el fin de caracterizar la representación de partes esqueletales, como también la estimación del Número Mínimo de Individuos (MNI). Los \%MAU fueron correlacionados con diversos índices asociados al aprovechamiento de diversos productos (carne, médula y grasa) para evaluar tendencias que pudieran estar relacionas con criterios de selectividad.

El aprovechamiento de los recursos faunísticos involucra una secuencia de actividades que implican una desorganización anatómica progresiva de las carcasas desde los lugares de obtención a los de consumo final. Para abordar este punto se utilizaron la frecuencia y abundancia relativa de partes esqueletales (MNE y \%MAU) y el Índice de Completitud Anatómica, con el fin de medir cuán completas se encontraban las carcasas representadas. Este índice fue calculado comparando el total de elementos recuperados a base del MNE y el número total de elementos esperados a base de MNI para todos los huesos que poseen algún recurso alimenticio asociado (carne, médula o ambos), considerando los elementos axiales y apendiculares por separado (Mengoni-Goñalons 1999).

Para el estudio de la anatomía económica se utilizaron el Índice de Utilidad propuesto por Borrero (1990) para el guanaco y modificado por Lyman (1994), como también los índices de Cavidad Medular y Secado (De Nigris y Mengoni-Goñalons 2004; Mengoni-Goñalons 1996). Para afinar la escala, se dividieron las distintas porciones de la carcasa de acuerdo con el producto primario que predomina en cada una de ellas, considerando para ello ocho segmentos relacionados con la obtención de carne, médula y grasa (De Nigris y Catá 2005) (Tabla 2). Con el fin de estandarizar la frecuencia de cada uno de los segmentos se calculó la relación entre el MNE esperado y observado para cada uno de ellos (De Nigris 2009). El conjunto fue dividido para efectos del análisis en dos grandes categorías etarias: adultos y jóvenes. Esta última se encuentra compuesta por subadultos y juveniles (Kauffman 2009). Para la asignación a cada categoría etaria se consideró el análisis de erupción y desgaste dental, fusión de huesos largos, lateralidad y datos osteométricos (Kauffman 2009; Puig y Monge 1983), por lo que algunas muestras corresponden a rangos más amplios, mientras que otras a categorías más precisas.

Tabla 2. Segmentos de la carcasa y productos primarios tomados de De Nigris (2009), De Nigris y Catá (2005). Carcass segments and primary products from De Nigris (2009), De Nigris and Catá (2005).

\begin{tabular}{ccc}
\hline Segmento & Unidades anatómicas & Producto primario (carne, grasa, médula) \\
\hline Cabeza & Cráneo y mandíbula & Órganos ricos en grasa \\
Columna & Vértebras cervicales, torácicas, & Proporciones de carne significativas \\
Costillar & lumbares y sacro & \\
Cinturas & Escápula e innominado & Proporciones de carne significativas \\
Extremidades superiores & Fémur y húmero & Proporciones de carne significativas \\
Extremidades medias & Radioulna y tibia & Carne y médula \\
Extremidades bajas & Metapodios & Proporciones moderadas de carne y médula \\
Patas y calcáneo & Falanges y calcáneo & Moderada proporción de médula \\
\end{tabular}


Para fines del análisis de distribución espacial todas las evidencias con un tamaño superior a los $5 \mathrm{~cm}$, entre ellos los restos óseos (principalmente de guanacos) y líticos, fueron registrados en planta durante la excavación, metodología aplicada también a rasgos como fogones o acumulaciones de pigmento.

\section{Procesamiento, Consumo, Tecnología Ósea y Distribución Espacial}

\section{Representación taxonómica}

El conjunto arqueofaunístico del sitio se compone principalmente de restos de guanacos, junto a taxa de menor tamaño como roedores, reptiles, cánidos, félidos, mustélidos y aves (Tabla 3). En el caso de los guanacos se observó un morfotipo de gran tamaño, con una distribución biogeográfica asociada directamente al valle, a decir, por las firmas isotópicas de todas las muestras analizadas (López et al. 2015).

Las alteraciones producidas por agentes naturales en la muestra son escasas. El 89,2\% de los huesos no presenta signos de meteorización, mientras que en el 10,8\% restante se observaron signos iniciales de exposición. En el caso de los restos con signos de meteorización, los mismos se concentran en el sector Este del sitio (Área de Actividad), en donde se observaron apilamientos de huesos, principalmente de guanacos. Por su parte, tan solo $0,56 \%$ de restos óseos presentan marcas atribuibles a carnívoros que por su tamaño corresponderían a cánidos como zorros, mientras que $0,04 \%$ presenta rastros del paso de incisivos de roedores sobre las superficies óseas. Los rastros tafonómicos con mayor frecuencia corresponden a marcas de pisoteo en 14,1\% concentradas en los restos de las unidades E17, F17, E16, F16, E15 y F15; emplazadas al centro del Área de Actividad.

\section{Perfil anatómico}

Al comparar la relación axial/apendicular para los individuos adultos $(1,6)$ y jóvenes $(1,4)$, esta es muy similar en ambos casos a lo esperado por individuo (Mengoni 1999). En el caso de los adultos

Tabla 3. Taxones identificados en el sitio MAU085 del Valle de Mauro separados por capas estratigráficas. La Capa B corresponde a la ocupación AT. Los números están expresados en NISP.

Identified taxa in the Mauro Valley MAU085 site, separated by stratigraphic layers. Layer B corresponds to the Late Archaic Period (AT). Numbers are expressed in NISP values.

\begin{tabular}{|c|c|c|c|c|c|c|}
\hline Taxa & Nombre común & Superficie & Capa A & Capa B & Capa C & Total \\
\hline Mammalia & Mamífero indeterminado & 1.744 & 49.921 & 154.855 & 5.241 & 211.761 \\
\hline Lama guanicoe & Guanaco & 9 & 875 & 4.415 & 173 & 5.472 \\
\hline Ave & Ave indeterminada & 0 & 0 & 0 & 0 & 0 \\
\hline Falconidae & Falcónido indeterminado & 0 & 0 & 5 & 0 & 5 \\
\hline Passeriforme & Passeriforme indeterminado & 0 & 0 & 1 & 0 & 1 \\
\hline Reptilia & Reptil indeterminado & 0 & 0 & 1 & 0 & 1 \\
\hline Callopistes sp. & Iguana chilena & 0 & 1 & 4 & 0 & 5 \\
\hline Liolaemus sp. & Lagartija & 0 & 0 & 1 & 0 & 1 \\
\hline Carnívora & Carnívoro indeterminado & 0 & 0 & 3 & 0 & 3 \\
\hline Canidae & Cánido indeterminado & 0 & 0 & 11 & 0 & 11 \\
\hline Lycalopex culpaeus & Zorro culpeo & 0 & 0 & 6 & 0 & 6 \\
\hline Lycalopex griseus & Zorro gris & 0 & 1 & 9 & 0 & 10 \\
\hline Mustelidae & Mustélido indeterminado & 0 & 0 & 1 & 0 & 1 \\
\hline Puma concolor & Puma & 0 & 1 & 1 & 0 & 2 \\
\hline Rodentia & Roedor indeterminado & 0 & 58 & 445 & 12 & 515 \\
\hline Abrocoma bennetti & Ratón chinchilla & 0 & 12 & 110 & 6 & 128 \\
\hline Akodon sp. & $\begin{array}{l}\text { Ratón con varias } \\
\text { denominaciones }\end{array}$ & 0 & 0 & 2 & 0 & 2 \\
\hline Octodon sp. & Ratón degú & 0 & 73 & 310 & 3 & 386 \\
\hline Spalacopus cyanus & Cururo & 0 & 0 & 18 & 1 & 19 \\
\hline Lagidium viscacia & Vizcacha & 0 & 13 & 75 & 2 & 90 \\
\hline Oryctolagus cuniculus & Conejo & 0 & 1 & 0 & 0 & 1 \\
\hline Indeterminado & Taxón indeterminado & 0 & 0 & 6 & 0 & 6 \\
\hline Total & & 1.753 & 50.956 & 160.279 & 5.438 & 218.425 \\
\hline
\end{tabular}


se observa un leve predominio del esqueleto axial. Los valores de completitud señalan que alrededor de $25 \%$ de las carcasas de los individuos adultos se encuentra representada tanto para el esqueleto axial como apendicular. No obstante, en el caso de los individuos jóvenes esta alcanza una representación extremadamente baja, de aproximadamente 4,3\% (Tabla 4). Con el fin de medir la incidencia de la densidad sobre la muestra de guanacos se correlacionaron los valores del \% MAU con los valores de densidad mineral ósea (Stahl 1999), tanto para el conjunto de animales adultos como jóvenes (no fusionados), observándose valores negativos aunque estadísticamente no significativos a los niveles usuales de confianza ( $\mathrm{p}>0,05)$ (Tabla 5).

El perfil anatómico, expresado mediante el $\% \mathrm{MAU}$, de las muestras de guanaco de la ocupación AT, indican para los animales adultos una frecuencia alta de cráneos y vértebras cervicales, y una frecuencia media de la escápula, más una baja representación del resto del esqueleto apendicular y axial. En los animales juveniles la frecuencia es similar, aunque en huesos como el fémur proximal, tibia proximal y distal la proporción es mayor en comparación a los animales adultos (Figura 3).

Los resultados obtenidos a partir de la correlación con el Índice de Utilidad de carne fueron en ambos casos positivos, y en el caso de los adultos, estadísticamente significativa ( $\mathrm{p} \leq 0,05)$, lo que sugiere una selectividad de partes en función del aporte cárneo. Por su parte, la correlación entre la representación de huesos largos y el volumen de cavidad medular fue positivo en ambos casos, no obstante, en los animales jóvenes es muy alto y estadísticamente significativo, lo que denota una alta selectividad para la obtención de médula ( $\mathrm{p} \leq$ 0,05). Finalmente para el Índice de Secado los resultados para el esqueleto axial y apendicular, si bien se observa una tendencia negativa, solo en el caso del esqueleto apendicular de juveniles se observa una correlación significativa, mientras que para los adultos no habría una selección de alguna de las regiones anatómicas para el secado de carne (Tabla 5 y Figura 4).

Al dividir el esqueleto en segmentos de acuerdo con sus productos primarios (Figura 5), en el caso de los adultos la mayor representación se observa en segmentos ricos en carne (columnas y cinturas) y órganos ricos en grasa (cabeza). Sin embargo, se observa una representación similar de segmentos en los cuales se combina carne y médula o solo médula. Esta tendencia también se observa para los individuos jóvenes, por lo que para subadultos y juveniles se estarían aprovechando los segmentos y sus productos primarios en forma similar. En relación con los segmentos pobremente representados como las costillas, un escenario plausible es el secado, como lo denotan

Tabla 4. Completividad anatómica para adultos y jóvenes (sensu Mengoni 1999).

Anatomical completeness (global, axial and appendicular) of adults and juveniles (sensu Mengoni 1999).

\begin{tabular}{ccc}
\hline Completividad anatómica & Adultos & Jóvenes \\
\hline Completividad anatómica global & 25,8 & 4,3 \\
Completividad anatómica axial & 26,9 & 4,2 \\
Completividad anatómica apendicular & 24,1 & 4,5 \\
\hline
\end{tabular}

Tabla 5. Resultado de las correlaciones entre el \%MAU con la Densidad Mineral Ósea (Stahl 1999), Índice de utilidad de carne (Borrero 1990), Índice de cavidad medular (Mengoni-Goñalons 1996) e Índice de secado para el esqueleto axial y apendicular (De Nigris y Mengoni-Goñalons 2004).

Correlation results between \%MAU and bone density (Stahl 1999), Meat Utility Index (Borrero 1990), Marrow Index (MengoniGoñalons 1996) and Drying Utility Index for the axial and appendicular skeleton (De Nigris and Mengoni-Goñalons 2004).

\begin{tabular}{cccccc}
\hline Grupo etario & $\begin{array}{c}\text { Densidad } \\
\text { Mineral Ósea }\end{array}$ & $\begin{array}{c}\text { Utilidad } \\
\text { económica }\end{array}$ & $\begin{array}{c}\text { Cavidad } \\
\text { medular }\end{array}$ & $\begin{array}{c}\text { IS } \\
\text { (axial) }\end{array}$ & $\begin{array}{c}\text { IS } \\
\text { (apendicular) }\end{array}$ \\
\hline Adultos & $r_{s}=-0,261$ & $r_{s}=0,515$ & $r_{s}=0,220$ & $r_{s}=-0,371$ & $r_{s}=-0,133$ \\
& $p=0,087$ & $p=0,000$ & $p=0,615$ & $p=0,419$ & $p=0,696$ \\
Juveniles & $r_{s}=-0,631$ & $r_{s}=0,683$ & $r_{s}=0,854$ & $r_{s}=-0,314$ & $r_{s}=-0,658$ \\
& $p=0,884$ & $p=0,192$ & $p=0,012$ & $p=0,564$ & $p=0,028$ \\
\hline
\end{tabular}




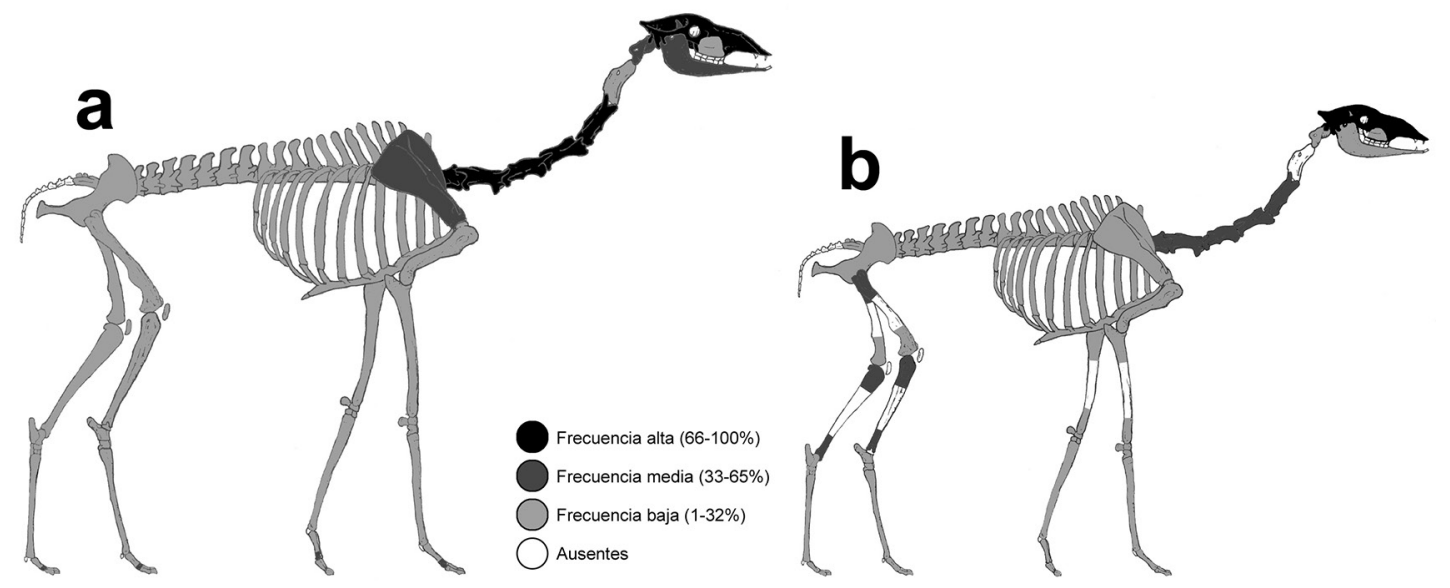

Figura 3. Representación gráfica del \%MAU para los restos de guanacos adultos (A) y juveniles (B) de la ocupación Arcaico Tardío del sitio MAU085.

Graph of \%MAU of adult (A) and juvenile (B) guanaco remains of the Late Archaic occupation in the MAU085 site.

los valores negativos (aunque poco significativos) del índice respectivo (Tabla 5). De esta manera, los resultados obtenidos indicarían un pocesamiento selectivo de ciertas partes anatómicas en el cual se aprovecharon los diferentes productos primarios, ya que se observa una selectividad de unidades en función de su carne, médula y grasa.

Por último, 1.229 especímenes, lo que equivale al $0,77 \%$ de la muestra total, presentan signos de exposición al fuego. De este conjunto, 604 restos presentan una exposición leve (quemados), 464 presentan un estado más avanzado (carbonizados) y 161 especímenes se encuentran calcinados. Durante el AT se desconocen recipientes apropiados para la cocción, por lo que la preparación de alimentos debió estar mediatizada por la exposición directa sobre el fuego de las presas capturadas, sobre una superficie calentada como rocas, por el ahumado, o bien mediante el consumo crudo o seco. Es por esta razón que los restos quemados podrían ser el resultado de algún proceso de cocción ocasional, de su uso como combustible ocasional, o bien de su cercanía incidental a fogones.

\section{Perfil etario}

El perfil etario de los restos de camélidos está conformada por un $\mathrm{MNI}_{\text {adultos }}$ de 37 (\%MNI=39), un $\mathrm{MNI}_{\text {subadultos }}$ de $13(\% \mathrm{MNI}=14), \mathrm{MNI}_{\text {juveniles }}$ de 36 (\%MNI=38), un $\mathrm{MNI}_{\text {crías }}$ de 5 (\%MNI=5), y un $\mathrm{MNI}_{\text {neonato }}$ de 3 (\%MNI=3) (Tabla 6 y Figura 6$)$.
Si bien es posible establecer la presencia de grupos familiares (neonatos y crías), predominan los individuos adultos, subadultos y especialmente juveniles. Lo anterior sugiere que la matanza se habría sostenido en el tiempo, probablemente sobre grupos de machos y hembras expulsados de los grupos familiares (Franklin 1983; Raedecke 1979), con énfasis en la captura de guanacos con un tamaño provechoso en términos económicos y sin afectar a los grupos reproductivos. Las actividades de caza se habrían realizado posiblemente durante los meses de otoño-invierno, momento en que los camélidos descienden de la cordillera y se encuentran en alturas más moderadas.

Basado en modelos de mortandad como el de Stiner (1990), se observa un perfil coherente con eventos de caza de guanacos sostenidos durante al menos 1.300 años (Figura 6). No obstante, esta presión sostenida pudo afectar a largo plazo a los grupos de guanacos, lo que es interesante de abordar a futuro, considerando la escasa a casi nula frecuencia de restos de camélidos durante el PAT en el NSA, y que puede deberse a un posible proceso de intensificación en la explotación durante el AT a nivel local.

\section{Distribución Espacial}

La distribución vertical de las evidencias no presenta mayores problemas debido a la relativa 

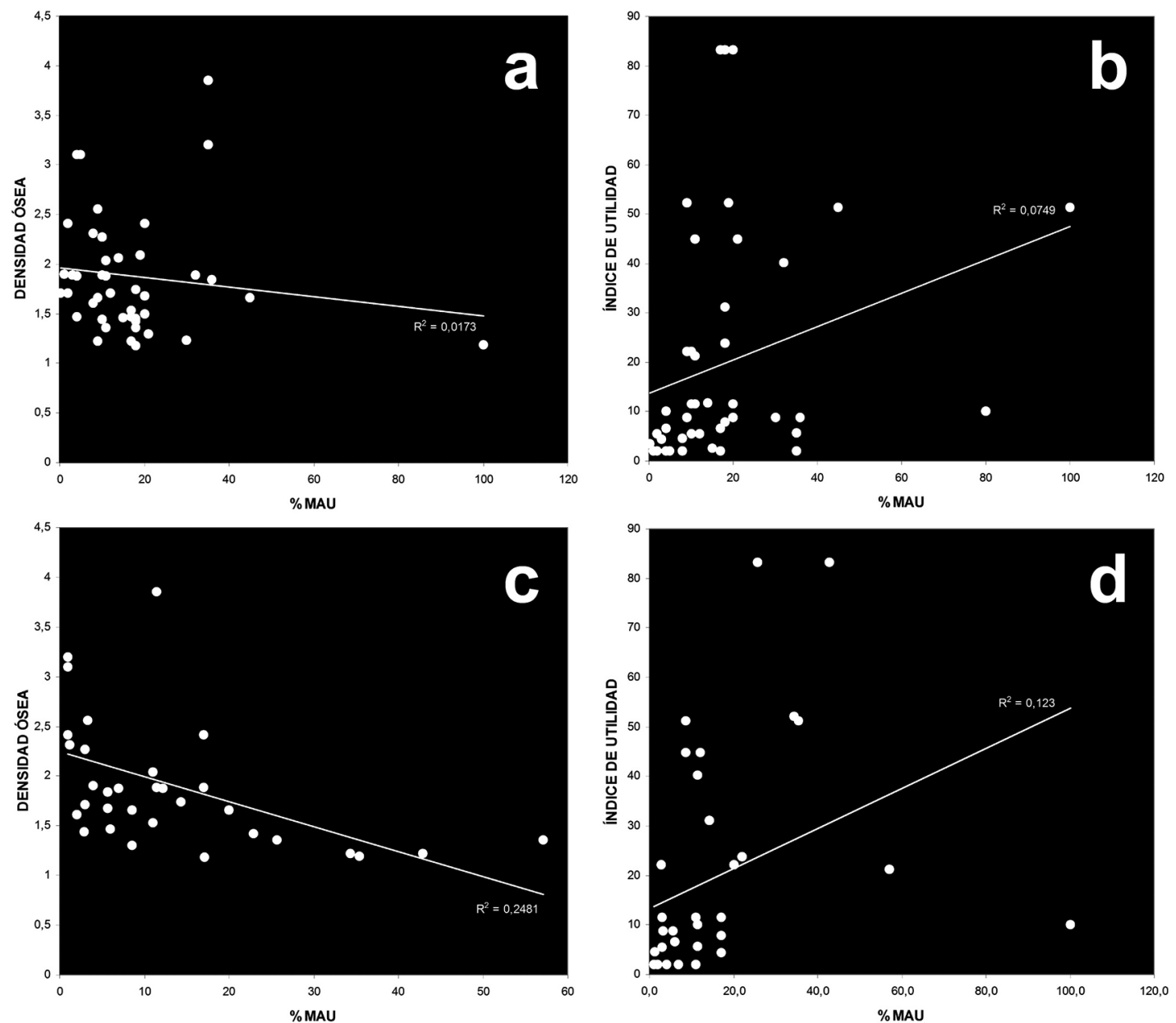

Figura 4. Gráficos de dispersión de: (A) Densidad ósea y \%MAU (guanacos adultos), (B) Índice de utilidad de carne y \%MAU (guanacos adultos, (C) Densidad ósea y \%MAU (guanacos juveniles), y (D) Índice de utilidad de carne y \%MAU (guanacos juveniles). Scatterplot of the relationship between: (A) bone density and \%MAU (adult guanacos), (B) Meat Utility Index and \%MAU (adult guanacos), (C) bone density and \%MAU (juvenile guanacos), and (D) Meat Utility Index and \%MAU (juvenile guanacos).

Tabla 6. Perfil etario (Rangos etarios) de los individuos de Lama guanicoe identificados en MAU085. Age profile (age ranges) of Lama guanicoe identified individuals in the MAU085 site.

\begin{tabular}{ccc}
\hline Rangos de edad & MNI & \%MNI \\
\hline Adultos: 37 a más 155 meses & 37 & 39 \\
Subadultos: $27-36$ meses & 13 & 14 \\
Juveniles: $16-26$ meses & 36 & 38 \\
Crías: 3 -12 meses & 5 & 5 \\
Neonatos & 3 & 3 \\
Total & 94 & 100 \\
\hline
\end{tabular}

horizontalidad de las capas identificadas y la presencia de dos estratos culturales de escasa profundidad (30 $\mathrm{cm}$ promedio para la Capa B y $20 \mathrm{~cm}$ para la
Capa A). La Capa B corresponde a un limo-arenoso muy carbonoso antropogénico y formado además por la descomposición de elementos orgánicos. Los 


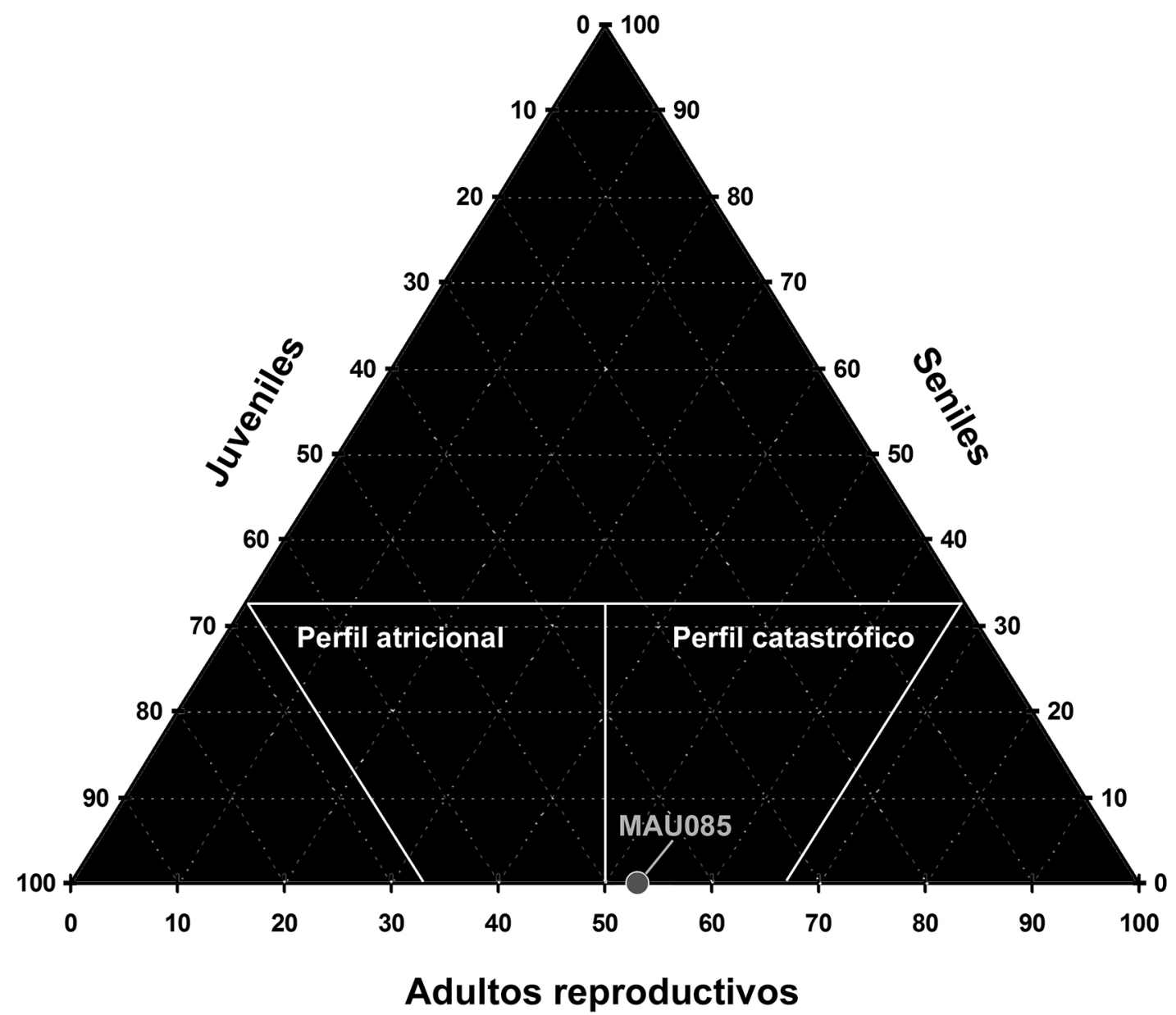

Figura 5. Relación entre el MNE esperado y el MNE observado para los segmentos de la carcasa de adultos y jóvenes en MAU085. Relation between the expected and observed MNE carcass segments of adults and juveniles in the MAUO85 site.

principales agentes de disturbación de esta capa corresponden a raíces de árboles que profundizan al menos hasta los $50 \mathrm{~cm}$, siendo áreas que fueron discriminadas en casi todos los casos durante la fase de excavación.

Para caracterizar el área ocupacional se realizó un registro tridimensional y bidimensional de las evidencias. Se incluyeron clastos semiangulares sin alteraciones propios de la formación geológica del sitio, con el fin de identificar posibles áreas de limpieza para el uso de pisos apropiados para el asentamiento humano. Se debe considerar que la planta, debido a la escasa profundidad de los depósitos, consideró toda la Capa B y por tanto promedia actividades de intensidades disímiles durante al menos 700 años. En efecto, de acuerdo con la distribución de estos pisos ocupacionales promediados se identificaron acumulaciones intencionales de rocas naturales, sobre todo en los sectores este y norte del sitio, despejando el centro y sectores oeste y sur que es donde se concentran los fogones. Estos rasgos corresponden tanto a fogones planos como en cubeta (Leroi-Gourhan 1979), con uno de ellos tapado por rocas a modo de delimitar su ubicación en el espacio para una posible reutilización del mismo. Estos fogones tienen un diámetro máximo de $40 \mathrm{~cm}$, siendo áreas acotadas asociadas a actividades de quema que incorporaron un escaso número de personas, o bien que fueron elaborados sincrónicamente para y por varios individuos para actividades de congregación y no necesariamente de preparación 


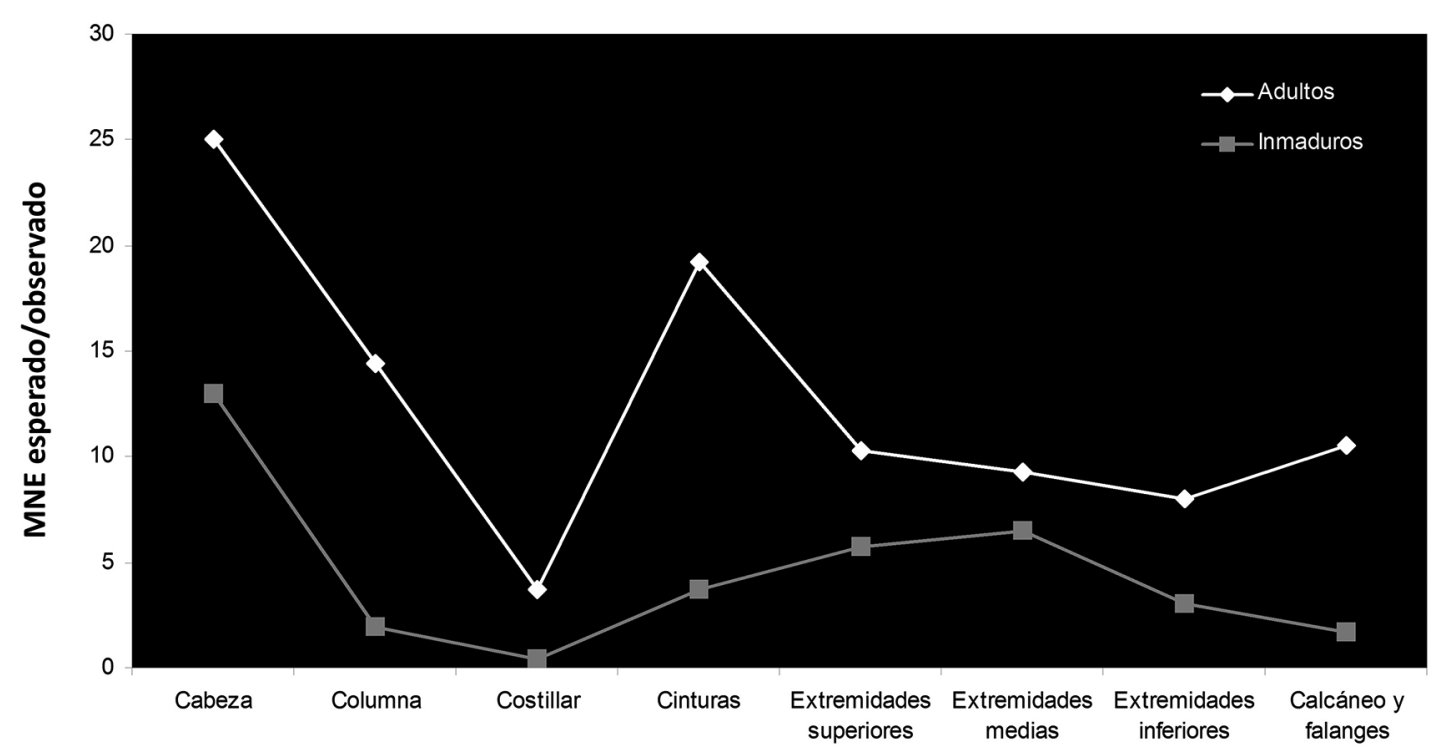

Figura 6. Diagrama ternario del perfil de mortandad con la ubicación de los camélidos de MAU085 de acuerdo con sus rangos de edad: juveniles (0-24 meses), adultos reproductivos (24-84 meses) y seniles (más de 84 meses).

Ternary diagram (analysis of mortality profile) indicating three age classes: juvenile (0-24 months), reproductive adults (24-84 months) and senile (more than 84 months) for the guanacos of the MAU085 site.

de alimentos. Al respecto, se debe considerar la muy baja representación de huesos con rastros de exposición al fuego, siendo el contenido de algunos fogones principalmente semillas y carporrestos en general (Belmar y Quiroz 2011).

En la Figura 7A se observa la distribución de restos óseos considerando tanto fragmentos identificados como de mamíferos indeterminados -aunque por tamaño y densidad deben corresponder a guanaco-, y en la Figura 7B se observa la distribución de restos líticos, considerando tanto artefactos de molienda, puntas de proyectil, raspadores, cuchillos, bifaces, unifaces, cepillos, raederas, tajadores y chopping tools, además de artefactos pulidos como micromorteros, pulidores, sobadores de cuero, ganchos de estólicas, entre otros. Ambas distribuciones difieren en la densidad de materiales en sectores específicos del área estudiada. En el caso de los restos óseos, se observan pequeñas concentraciones en las unidades F15, F16, H16, H17 y G19. Las últimas tres unidades son de especial interés, por cuanto conforman un apilamiento de restos óseos más íntegros en comparación al resto de las unidades. Tal apilamiento se condice con posibles zonas de descarte y/o bien múltiples actividades de limpieza del sitio, sobre todo de restos como los faunísticos, proclives a generar más "contaminación" en áreas enfocadas a actividades domésticas. Estas acumulaciones no están asociadas a fogones y presentan un escaso registro de restos líticos, lo que apunta a un sector seleccionado a modo de área de descarte monocomponente. Los resultados permiten inferir la presencia de un espacio ordenado en función de las diversas actividades, con áreas de tránsito y procesamiento primario-secundario delimitadas y caracterizadas por una mayor frecuencia de astillas óseas de tamaño pequeño, además de áreas de descarte segregadas con unidades óseas más completas.

Asimismo, fogones en cubeta como el observado en el sitio implican una inversión mayor de energía para la elaboración de estas estructuras, lo que puede asociarse a ocupaciones más intensas (Frank 2012). Es llamativo que el fogón en cubeta más estructurado haya sido deliberadamente tapado con rocas para delimitar su ubicación para su posible reutilización. El uso de fogones respondería a múltiples funciones, preparación de pigmentos, y tratamientos térmicos en restos líticos y astiles, como se ha identificado en parte de las evidencias de MAU085 (Jackson y Peralta 2011). En tal sentido, la recurrencia de restos líticos y óseos alrededor de los fogones en 

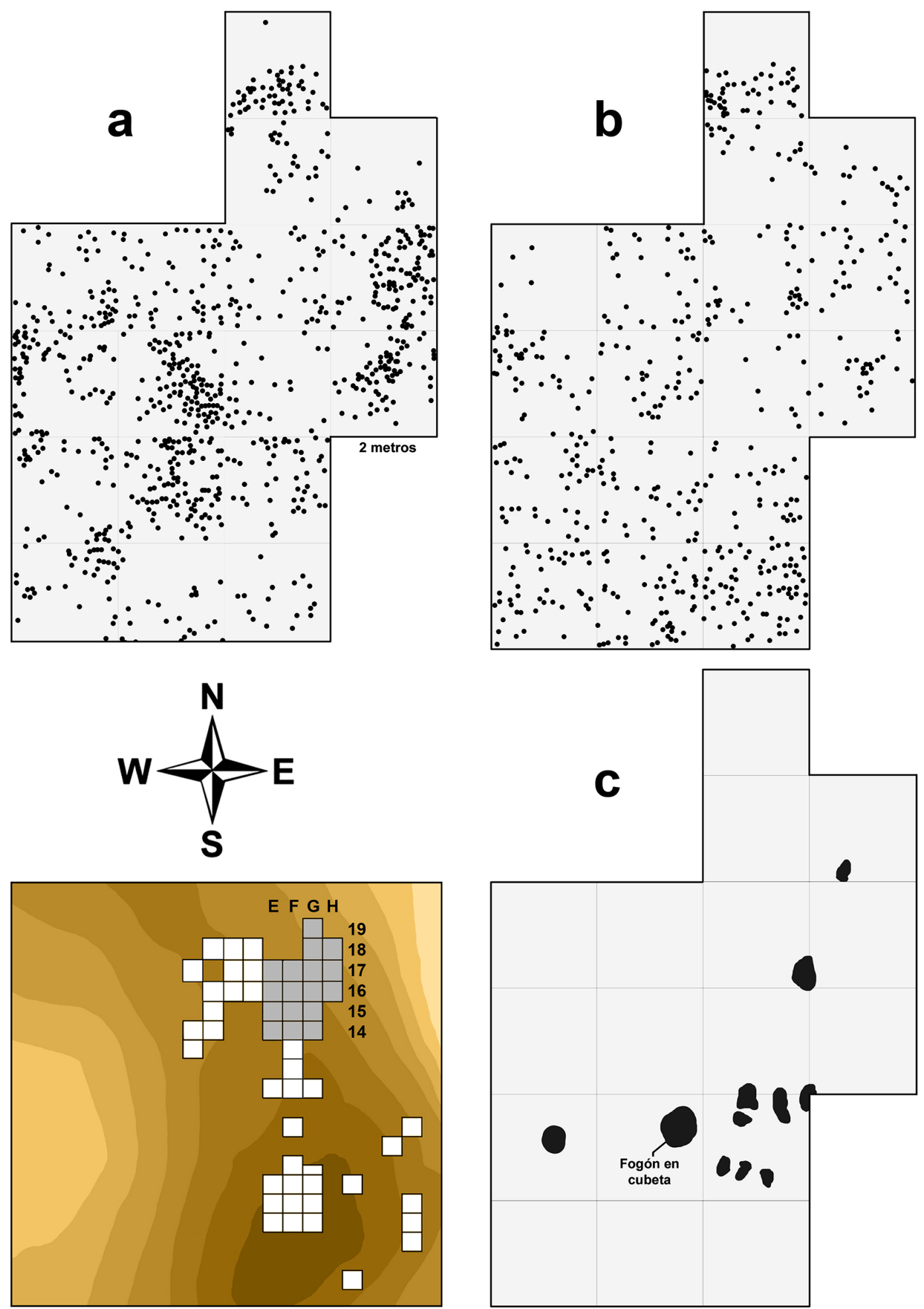

Figura 7. (A) Distribución de restos óseos en Área de Actividad, (B) distribución de restos líticos en Área de Actividad, (C) distribución de fogones.

(A) Bone distribution in the "Activity Area", (B) Lithic remains distribution in the "Activity Area", (C) Fireplaces distribution. 
el sitio es esperable, de acuerdo con las tendencias observadas etnográficamente en grupos cazadoresrecolectores (Binford 1994; Chatters 1987; Henry 2012; O'Connell 1987). Sin embargo, el bajo diámetro de estas estructuras de combustión y la escasa dimensión vertical de los fogones planos apuntan a ocupaciones cortas en ciertos períodos del año (Bartram et al. 1991) (Figura 7C).

Por su parte, el registro lítico sugiere una estrategia tecnológica de tipo curatorial, con alta inversión de energía, alta formatización, buena calidad de materias primas y alto mantenimiento, características propias de grupos cazadores de alta movilidad (Jackson y Peralta 2011:28). La abundante frecuencia de materias primas de tipo silíceas involucra movimientos hacia fuentes de materias primas no identificadas pero presumiblemente ubicadas en zonas cordilleranas. Además, el análisis realizado desde un punto de vista tecnológico señala que la cadena operativa de artefactos formalizados como puntas de proyectil están representadas en su fase final, lo que podría indicar un asentamiento temporal y reiteradamente ocupado, con un traslado al sitio de artefactos en avanzado estado de manufactura desde otros campamentos (Jackson y Peralta 2011:27).

\section{Discusión y Conclusiones}

Un aspecto relevante a considerar, tiene que ver con la disposición geográfica del yacimiento, el cual se emplaza sobre una loma que posee buena visibilidad, transitando tanto desde el oeste como del este, con un fácil acceso a dos cursos de agua tanto al sur como al norte. Considerando la abundancia de guanacos cazados, la representación anatómica de estos animales en el sitio, y la escasa a casi nula recurrencia de ocupaciones sincrónicas en el valle, es posible plantear que su emplazamiento fue elegido por su estratégica ubicación para la obtención de recursos animales predecibles en ciertas épocas del año.

Así como en la costa se ha observado para el lapso que va entre los 4.000 a 2.000 años a.p. un amplio conocimiento de la distribución local de materias primas dentro de un sistema de movilidad residencial hacia recursos predecibles (Méndez y Jackson 2004), el asentamiento intravalle en Mauro debió considerar la predictibilidad del recurso animal con el fin de obtener una biomasa importante mediante estrategias de intercepción y caza. En recientes análisis de isótopos de Nitrógeno y Carbono a partir de restos humanos de los sitios MAU033 y MAU085 se identificaron dietas de recursos propios del valle, sin firmas isotópicas asociadas al consumo de recursos de la costa (Pacheco y Gómez 2012). Estos análisis apuntan a que los habitantes de MAU085 y MAU033 corresponden a grupos que se movilizan entre los valles interiores y la cordillera. Bajo esta idea de movilidad intervallecordillera, el recurso animal sería crítico, en especial el guanaco, ya que otorga la mayor cantidad de biomasa consumible en comparación a la oferta de los recursos costeros.

La evidencia sugiere entonces un espacio utilizado recurrentemente pero de manera estacional y por cortos períodos de tiempo. Las actividades realizadas habrían estado enfocadas principalmente en la caza, explotación y procesamiento de guanacos, resultante en un aprovechamiento de productos primarios y secundarios. A pesar que las correlaciones del Índice de Secado no fueron significativas en la mayoría de los casos, el bajo número de costillas reperesentadas en comparación a otras porciones esqueletales (De Nigris y Mengoni-Goñalons 2004), junto a los valores obtenidos para el esqueleto apendicular, sugieren que algunas unidades podrían haber sido seleccionadas para la elaboración de ch'arki o subproductos de carne preparados para una mayor duración. Estas secciones pudieron ser trasladadas a otros asentamientos del mismo valle o bien fuera de este mediante circuitos de movilidad.

La evidencia lítica señala actividades asociadas al reavivamiento de filos de puntas de proyectil y el recambio de aquellas fracturadas por las actividades cinegéticas, lo que es coherente con la alta frecuencia de bases de puntas en el sitio (Jackson y Peralta 2011). Además, el instrumental lítico incluye numerosos artefactos relacionados con el procesamiento de las carcasas y los productos primarios (cuchillos, raspadores, raederas, tajadores, entre otros). Es importante mencionar que los artefactos óseos recuperados indican además la preparación de pieles y fibras, aspecto observado a partir del análisis mediante microscopía electrónica de barrido (Santander y López 2012). Junto a las actividades antes mencionadas, el sitio presenta una alta complejidad en cuanto a la representación de otras esferas tanto de la vida diaria como también la presencia de entierros, lo que nos lleva a evaluar las características de los sitios de grupos con una alta movilidad, en los que las categorías 
comúnmente utilizadas para describir dichos contextos arqueológicos presentan diversos grados de ambigüedad y traslape (Binford 1980; Bettinger 1991)

Por último, este acercamiento al registro osteofaunístico del sitio MAU085 no solo ofrece antecedentes relevantes para las ocupaciones arcaicas en el área, sino que aporta también a la discusión de las primeras sociedades alfareras del valle y de gran parte del semiárido chileno. Recientes evaluaciones arqueológicas del PAT apuntan a grupos altamente móviles (Pavlovic 2004; Troncoso et al. 2012) y con una notoria orientación a la recolección. Esta tendencia ha sido observada isotópicamente en restos humanos de distintos sitios PAT del valle de Mauro, en donde se han identificado firmas isotópicas que marcan una muy baja ingesta de proteína animal, reemplazada por proteínas de vegetales tipo $\mathrm{C}_{3}$ (Pacheco y Gómez 2012). ¿A qué se debe este cambio en la explotación de recursos en un lapso de 500 años, al menos en el valle de Mauro? Esta pregunta se extiende para todo el PAT en su fase inicial, debido a la persistente baja frecuencia de restos faunísticos que denotan gran parte de los sitios excavados del período. Consideramos que un punto a abordar en esta transición arcaica-alfarera es la sobreexplotación del guanaco debido al incremento en la presión de caza evidenciada en sitios como MAU085, potenciada por desbalances entre las poblaciones locales y los recursos. Este fenómeno ha sido observado en áreas colindantes cerca de los 2.000 años a.p. (Neme et al. 2012), así como en el mismo valle. Al respecto, evidencias como el aumento del tamaño corporal de los camélidos durante el AT y su disminución en el PAT y PIT no ha sido estudiado en profundidad y requerirán de una mayor discusión que involucre a modelos ecológicos no utilizados en estudios previos. Este es un problema que quedará en la agenda de trabajo y que potenciará la discusión para todo el Norte Semiárido de Chile.

Agradecimientos: Este trabajo fue financiado por el "Proyecto Arqueológico Mauro". Nuestros agradecimientos a Daniel Pavlovic por toda la ayuda aportada durante el desarrollo de la investigación. Agradecemos además a Camila Opazo, María Paz Casorzo, Douglas Jackson, y Jennifer Pavez por su ayuda durante el proceso de análisis de las muestras y a todo al equipo que participó durante las distintas fases de excavación. Por último, nuestros agradecimientos a los evaluadores anónimos, cuyas sugerencias y comentarios permitieron mejorar una primera versión del manuscrito.

\section{Referencias Citadas}

Ampuero, G. y M. Rivera 1971. Secuencia arqueológica del alero rocoso de San Pedro Viejo de Pichasca. Boletín del Museo Arqueológico de la Serena 14:45-69.

Bartram, L., E. Kroll y H. Bunn 1991. Variability in camp structure and bone food refuse patterning at Kua San hunter-gatherer camps. En The Interpretation of Archaeological Spatial Patterning, editado por E. Kroll y T. Price, pp. 77-148. Plenum Press, Nueva York.

Belmar, C. y L. Quiroz 2011. Análisis arqueobotánico del sitio MAU085. Manuscrito en posesión de las autoras.

Bettinger, R.L. 1991. Hunter-Gatherers: Archaeological and Evolutionary Theory. Plenum Press, Nueva York.

Binford, L. 1980. Willow smoke and dogs' tails: hunter-gatherer settlement systems and archaeological site formation. American Antiquity 45:4-20.

Binford. L. 1994. En Busca del Pasado. Descifrando el Registro Arqueológico. Crítica, Barcelona.

Borrero, L.A. 1990. Fuego-patagonian bone assemblages and the problem of communal guanaco hunting. En Hunters of the Recent Past, editado por L.B. Davis y B.O.K. Reeves, pp. 373 99. Unwin Hyman, Londres.

Bronk Ramsey, C. 2008. Deposition models for chronological records. Quaternary Science Reviews 27:42-60.
Bronk Ramsey, C. 2009. Bayesian analysis of radiocarbon dates. Radiocarbon 51:337-360.

Bronk Ramsey, C. y S. Lee 2013. Recent and planned developments of the program OxCal. Radiocarbon 55:720-730.

Cornejo, L. y D. Jackson 2004. Un panorama del patrón de asentamientos en los esteros Conchalí-Pupío (Los Vilos): entre el interior y la costa. Revista Werken 5:83-87.

Chatters, J. 1987. Hunter-Gatherer adaptations and assemblage structure. Journal of Anthropological Archaeology 6:336-375.

De Nigris, M. 2009. Modelos de transporte etnoarqueológicos: sobre su aplicabilidad y pertinencia para el interior de Patagonia. En Temas de Arqueología 2: Estudios Tafonómicos y Zooarqueológicos, editado por A. Acosta, D. Loponte y L. Mucciolo, pp. 35-53. Instituto Nacional de Antropología y Pensamiento Latinoamericano, Buenos Aires.

De Nigris, M.E. y M.P. Catá 2005. Cambios en los patrones de representación ósea del guanaco en Cerro de los Indios 1 (Lago Posadas, Santa Cruz). Intersecciones en Antropología 6:109-119.

De Nigris, M. y G.L. Mengoni Goñalons 2004. El guanaco como fuente de carne y grasas en Patagonia. En Contra Viento y Marea. Arqueología de Patagonia, editado por M.T. Civalero, P.M. Fernández y A.G. Guráieb, pp. 469-476. Sociedad Argentina de 
Antropología e Instituto Nacional de Antropología y Pensamiento Latinoamericano, Buenos Aires.

Henry, D. 2012. The palimpsest problem, hearth pattern analysis, and Middle Paleolithic site structure. Quaternary International 247:246-266.

Frank, A. 2012. Los fogones en la meseta central de Santa Cruz durante el Pleistoceno Final. Magallania 40:145-162.

Franklin, W. 1983. Contrasting socioecologies of South America's wild camelids: the vicuña and the guanaco. En Advances in the Study of Mammalian Behavior, editado por J.F. Eisenberg y D.G. Kleinman, pp. 573-629. American Society of Mammalogist, Special Publication 7, Pittsburg.

Freeman L. 1978. Mousterian worked bone from Cueva Morin (Santander, Spain), a preliminary description. En Views of the Past, Essays in Old World Prehistory and Paleoanthropology, editado por L. G. Freeman, pp. 29-52. Aldine, Chicago.

Hogg, A.G., Q. Hua, P.G. Blackwell, M. Niu, C.E. Buck, T.P. Guilderson, T.J. Heaton, J.G. Palmer, P.J. Reimer, R.W. Reimer, C.S.M. Turney y S.R.H. Zimmerman 2013. SHCal13 Southern Hemisphere Calibration, 0-50,000 Years cal BP. Radiocarbon 55:1889-1903.

Jackson, D. y P. Peralta 2011. Análisis Lítico. Informe Inédito Proyecto "Rescate Sitios Arqueológicos Valle de Mauro". Manuscrito en posesión de las autores.

Kaufmann, C. 2009. Estructura de Edad y Sexo en Guanaco. Estudios Actualísticos y Arqueológicos en Pampa y Patagonia. Sociedad Argentina de Antropología, Buenos Aires.

Latorre, E. 2012. Análisis de minerales de contextos arqueológicos del Valle de Mauro. Manuscrito en poder de la autora.

Leroi-Gourhan, A. 1979. Structures de combustion et structures d'excavation. Revista do Museu Paulintas XXVI:9-10.

López, P., I. Cartajena, B. Santander, D. Pavlovic y D. Pascual 2015. Camélidos domésticos en el Valle de Mauro (Norte Semiárido, Chile): múltiples análisis para un mismo problema. Intersecciones en Antropología 16:101-114.

Lyman, R. L. 1994. Vertebrate Taphonomy. Cambridge University Press, Cambridge.

Méndez, C. y D. Jackson 2004. Ocupaciones humanas del Holoceno Tardío en Los Vilos (IV Región, Chile): Origen y características conductuales de la población local de cazadores recolectores de litoral. Chungara Revista de Antropología Chilena 36:279-293.

Méndez, C. y D. Jackson 2008. La ocupación prehispánica de Combarbalá (Norte Semiárido, Chile): una propuesta sintética. Chungara Revista de Antropología Chilena 40:5-17.

Méndez, C., A. Troncoso, D. Jackson y D. Pavlovic 2009. Movilidad y uso del espacio entre cazadores-recolectores tardíos en espacios cordilleranos del Norte Semiárido de Chile. Intersecciones en Antropología 10:311-326.
Mengoni-Goñalons, G.L. 1996. La domesticación de los camélidos sudamericanos y su anatomía económica. En Zooarqueología de Camélidos 2. Grupo Zooarqueología de Camélidos, editado por D. Elkin, C. Madero, G. Mengoni-Goñalons, D. Olivera, M. Reigadas y H. Yacobaccio, pp. 33-45. Grupo Zooarqueología de Camélidos, Buenos Aires.

Mengoni-Goñalons, G.L. 1999. Cazadores de Guanaco de la Estepa Patagónica. Sociedad Argentina de Antropología, Colecciones Tesis Doctorales, Buenos Aires.

Neme, G., S. Wolverton y A. Gil 2012. Modelo ecológico para evaluar la sobreexplotación de ungulados: implicancias en los conjuntos zooarqueológicos de guanaco del sur de Mendoza. Archaeofauna 21:207-218.

O'Connell, J. 1987. Alyawara site structure and its archaeological implications. American Antiquity 52:74-108.

Pacheco, A. y P. Gómez 2012. Informe de las dataciones radiocarbónicas y de los análisis de proporciones isotópicas en restos humanos Arqueológicos Valle del Mauro. Área de Bioantropología. Manuscrito en poder de los autores.

Pavlovic, D. 2004. Dejando atrás la tierra de nadie: asentamientos, contextos y movilidad de las comunidades alfareras tempranas del Choapa. Revista Werken 5:39-46.

Pavlovic, D., D. Pascual, S. Alfaro y C. Cortés 2011. Análisis de materiales arqueológicos del sitio MAU085. Manuscrito en poder de los autores.

Puig, S. y S. Monge 1983. Determinación de la edad en Lama guanicoe (Müller). Deserta 7:246-270.

Raedecke, K. 1979. El Guanaco de Magallanes, Chile. Distribución y Biología. Corporación Nacional Forestal (CONAF), Santiago.

Santander, B. y P. López 2012. Análisis de microhuellas de uso mediante Microscopio Electrónico de Barrido (MEB) de artefactos óseos de un sitio Arcaico Tardío del Valle de Mauro (Región de Coquimbo, Chile): aportes para una reconstrucción contextual. Revista Chilena de Antropología 26:129-150.

Solar, C., C. Méndez, D. Jackson y P. López 2010. Tecnología lítica y áreas de actividad en un contexto de cazadoresrecolectores en el Norte Semiárido de Chile. Revista Chilena de Antropología 22:57-76.

Stiner, M.C. 1990. The use of mortality patterns in archaeological studies of hominid predatory adaptations. Journal of Anthropological Archaeology 9:305-351.

Troncoso, A., P. Larach, S. Alfaro, D. Pascual y D. Pavlovic 2012. Nuevos antecedentes para el Período Alfarero Temprano en el Valle del Choapa: el sitio Los Mellizos (cuenca superior del río Illapel). En Actas del XVIII Congreso Nacional de Arqueología Chilena, editado por Sociedad Chilena de Arqueología, pp. 309319. Gráfica LOM Ltda., Santiago.

Veit, H. 1993. Upper Quaternary landscape and climate evolution in the Norte Chico (Northern Chile): An overview. Mountain Research Development 13:139-144.

\section{Nota}

1 Se presentan los resultados de las unidades excavadas antes de 2013. 